Original Article

\title{
The intra- and inter-rater reliabilities of the Short Form Berg Balance Scale in institutionalized elderly people
}

\author{
SeONG-Gil Kim, PT, PhD ${ }^{1)}$, Myoung-Kwon Kim, PT, PhD²)* \\ 1) Department of Physical Therapy, Uiduk University, Republic of Korea \\ 2) Department of Physical Therapy, College of Rehabilitation Science, Daegu University: 15 Jillyang, \\ Gyeongsan-si, Gyeongbuk 712-714, Republic of Korea
}

\begin{abstract}
Purpose] The purpose of this study was to examine the intra- and inter-rater reliabilities of the Short Form Berg Balance Scale in institutionalized elderly people. [Subjects and Methods] A total of 30 elderly people in a nursing facility in Y city, South Korea, participated in this study. Two examiners administered the Short Form Berg Balance Scale to one subject to investigate inter-rater reliability. After a week, the same examiners administered the Short Form Berg Balance Scale once more to investigate intra-rater reliability. [Results] The intra-rater reliability was 0.83 . The inter-rater reliability was 0.79 . Both reliabilities were high (more than 0.7 ). [Conclusion] The Short Form Berg Balance Scale is a version of the Berg Balance Scale shortened by reducing the number of items, but its reliabilities were not lower than those of the Berg Balance Scale. The Short Form Berg Balance Scale can be useful clinically due to its short measurement time.

Key words: Balance, Elderly, Reliability
\end{abstract}

(This article was submitted Apr. 16, 2015, and was accepted May 25, 2015)

\section{INTRODUCTION}

Generally, gravity is applied to the body from the top down. Muscles support the body and create motions against gravity. When a force is generated, another force is also generated in the opposite direction, and this was generalized by "the law of action and reaction" by Newton".

The original force and opposite force are generated when the body moves, and gravity, a third force, is also applied to the body. Therefore, the balance of these three forces should be well controlled to create intended movements ${ }^{1)}$. Even while standing still, that is, supporting the body but not moving, people are able to hold their position because these three forces are balanced. The ability to balance these three forces is called balance control ability, and it plays an important role in daily activities ${ }^{2}$.

Balance ability varies from person to person and generally decreases as people age ${ }^{3)}$. A decrease in balance control ability to below a certain level can cause falling, which may lead to severe injury in the elderly).

The Berg Balance Scale (BBS) is a representative tool for fall prediction in the elderly that measures balance ability. This tool is widely used, as it is recognized as being objec-

*Corresponding author. Myoung-Kwon Kim (E-mail: kimmk@daegu.ac.kr)

C2015 The Society of Physical Therapy Science. Published by IPEC Inc. This is an open-access article distributed under the terms of the Creative Commons Attribution Non-Commercial No Derivatives (by-ncnd) License $<$ http://creativecommons.org/licenses/by-nc-nd/3.0/>. tive and reliable, and static and dynamic balance abilities can be evaluated overall and item by item ${ }^{5}$. The evaluation time for this tool is about 20 minutes. A recent study developed the Short Form Berg balance Scale (SFBBS), which has a reduced number of items, to decrease the measurement time but produce similar measurement results ${ }^{6}$. . However, there is a lack of research regarding the reliability of the SFBBS. Therefore, this study investigated the inter- and intra-rater reliabilities of the SFBBS.

\section{SUBJECTS AND METHODS}

This study was conducted with 30 elderly people with a mean age, height, and weight of $75.1 \pm 7.2$ years, $159.1 \pm 6.4 \mathrm{~cm}$, and $56.3 \pm 3.8 \mathrm{~kg}$, and all were residing in a nursing facility in Y city, South Korea. The selection criteria for the subjects were as follows: (1) at least 65 years old, (2) at least one fall experience within the last year, (3) no visual impairment or severe somatosensory damage, (4) ability to walk at least $10 \mathrm{~m}$ without aid, (5) no pain that might affect gait, and (6) a sufficient level of consciousness to conduct the experiment. Information about the study was provided to the subjects before their participation in accordance with the ethical principles of the Declaration of Helsinki, and all agreed to participate in the project by providing written informed consent.

The balance abilities of the subjects were measured with the SFBBS. The SFBBS has fewer items than the BBS, which objectively evaluates static and dynamic balance ability. It has 7 core items selected from the 14 items of the BBS. The SFBBS turned out to be more efficient than the 
BBS because it is simple and quick and generates the same results as the BBS. The 7 items can be divided into $3 \mathrm{sec}-$ tions: standing, sitting, and changing posture. The items are scored on a scale of 0 to 4 , and the maximum score is 28 . Higher scores indicate better balance ability ${ }^{6}$.

Two examiners measured the SFBBS of one subject to investigate the inter-rater reliability. After a week, the same examiners measured the SFBBS once more to investigate intra-rater reliability. The examiners and subjects were informed about the measurement method before the test. All the measurements are reported as the mean value \pm standard deviation

IBM SPSS Statistics for Windows (version 20.0) was used to analyze the data. The intraclass correlation coefficient (ICC) was used to examine the intra- and inter-rater reliabilities. The statistical significance level used was $\alpha=$ 0.05 .

\section{RESULTS}

The intra-rater reliability was $0.83(\mathrm{p}<0.05)$. The interrater reliability was $0.79(\mathrm{p}<0.05)$. The intra- and inter-rater reliabilities were high, that is, more than 0.7 (Table 1).

\section{DISCUSSION}

The BBS is a balance ability evaluation tool being used all over the world for diverse people. There are many studies demonstrating the reliability of the BBS.

The previous studies on intra-rater reliability, which indicates whether or not an examiner obtains consistent outcomes, showed excellent reliability $(\mathrm{ICC}=0.97$ ) for normal elderly people ${ }^{5)}$ and excellent reliability $(\mathrm{ICC}=0.77)$ for institutionalized elderly people as well ${ }^{7}$.

A study on inter-rater reliability, which indicates the degree of agreement of outcomes obtained by two examiners, showed excellent reliability $(\mathrm{ICC}=0.88)$ for institutionalized elderly people ${ }^{7)}$.

As indicated above, there are many studies demonstrating the reliability of the BBS in the elderly. However, there are few previous studies of the SFBBS. A previous study of the SFBBS showed excellent reliability $(\mathrm{ICC}=0.95)$ for the elderly by investigating its test-retest reliability ${ }^{6}$. It contains fewer items than the BBS, but its reliability is only slightly decreased.

This study investigated the intra- and inter-rater reli-
Table 1. Intra-rater and inter-rater reliabilities of the SFBBS

\begin{tabular}{|c|c|c|c|}
\hline & \multicolumn{2}{|c|}{ Measurement } & ICC \\
\hline \multirow[t]{2}{*}{ Intra } & 1 st & 2nd & $0.83^{*}$ \\
\hline & $17.92 \pm 4.97$ & $20.84 \pm 4.38$ & \\
\hline \multirow[t]{2}{*}{ Inter } & Examiner 1 & Examiner 2 & $0.79 *$ \\
\hline & $17.20 \pm 5.26$ & $19.00 \pm 3.80$ & \\
\hline
\end{tabular}

Mean \pm SD. ${ }^{*} p<0.05$. ICC: intraclass correlation coefficient

abilities of the SFBBS in institutionalized elderly people. The intra-rater reliability was high $(\mathrm{ICC}=0.83)$, and the inter-rater reliability was high $(\mathrm{ICC}=0.79)$. This indicates that reliability did not decrease that much even though the number of test items was reduced. The previous studies on the reliability of the BBS mentioned above showed that reliability in institutionalized elderly people was a little lower than that in normal elderly people. In this regard, the reliabilities obtained in this study are not lower than those of the BBS because the subjects in this study were also institutionalized elderly people. Therefore, the SFBBS is a version of the BBS shortened by reducing number of items, but its reliabilities were not lower than those of the BBS. The SFBBS can be useful clinically due to its short measurement time. However, a study of the validity of the SFBBS should be performed through follow-up testing.

\section{REFERENCES}

1) Katsura S, Matsumoto $\mathrm{Y}$, Ohnishi K: Realization of "law of action and reaction" by multilateral control. IEEE Trans, 2005, 52: 1196-1205.

2) Winter DA: Human balance and posture control during standing and walking. Gait Posture, 1995, 3: 193-214. [CrossRef]

3) Kim SG, Nam CW, Yong MS: The effect of increase in baggage weight on elderly women's lower extremity muscle activation during gait. Arch Gerontol Geriatr, 2014, 59: 574-576. [Medline] [CrossRef]

4) Han MJ, Yuk GC, Gak H, et al.: Acute effects of 5 min of plantar flexor static stretching on balance and gait in the elderly. J Phys Ther Sci, 2014 26: 131-133. [Medline] [CrossRef]

5) Berg KO, Maki BE, Williams JI, et al.: Clinical and laboratory measures of postural balance in an elderly population. Arch Phys Med Rehabil, 1992, 73: 1073-1080. [Medline]

6) Karthikeyan G, Sheikh SG, Chippala P: Test-retest reliability of short form of berg balance scale in elderly people. Glo Adv Res J Med Med Sci. 2012, 1: 139-144.

7) Holbein-Jenny MA, Billek-Sawhney B, Beckman E, et al.: Balance in personal care home residents: a comparison of the Berg Balance Scale, the Multi-Directional Reach Test, and the Activities-Specific Balance Confidence Scale. J Geriatr Phys Ther, 2005, 28: 48-53. [Medline] [CrossRef] 